\title{
Different impacts of respiratory symptoms and comorbidities on COPD-specific health-related quality of life by COPD severity
}

This article was published in the following Dove Press journal: International Journal of COPD

13 November 2017

Number of times this article has been viewed

Hyun Lee, ${ }^{1, *}$ Byung Woo Jhun, ${ }^{1, *}$ Juhee Cho, ${ }^{2-4}$ Kwang Ha Yoo, ${ }^{5}$ Jin Hwa Lee, ${ }^{6}$ Deog Kyeom Kim, ${ }^{7}$ Jong Deog Lee, ${ }^{8}$ Ki-Suck Jung, ${ }^{9}$ Jung Yeon Lee, ${ }^{10}$ Hye Yun Park'

'Division of Pulmonary and Critical Care Medicine, Department of Medicine, Samsung Medical Center, Sungkyunkwan University School of Medicine, Seoul, South Korea; ${ }^{2}$ Center for Clinical Epidemiology, Samsung Medical Center, Sungkyunkwan University School of Medicine, Seoul, South Korea; ${ }^{3}$ Department of Epidemiology, Johns Hopkins Bloomberg School of Public Health, Baltimore, MD, USA; ${ }^{4}$ Department of Clinical Research Design and Evaluation, Samsung Advanced Institute for Health Sciences and Technology, Sungkyunkwan University, Seoul, South Korea; ${ }^{5}$ Division of Pulmonary, Allergy and Critical Care Medicine, Department of Internal Medicine, Konkuk University School of Medicine, Seoul, South Korea; ${ }^{6}$ Division of Pulmonary and Critical Care Medicine, School of Medicine, Ewha Womans University, Seoul, South Korea; ${ }^{7}$ Division of Pulmonary and Critical Care Medicine, Department of Internal Medicine, Seoul Metropolitan Government-Seoul National University Boramae Medical Center, Seoul National University College of Medicine, Seoul, South Korea; ${ }^{8}$ Division of Pulmonary and Critical Care Medicine, Department of Internal Medicine, Gyeongsang National University Hospital, Jinju, South Korea; ${ }^{9}$ Division of Pulmonary, Allergy and Critical Care Medicine, Department of Internal Medicine, Hallym University Medical Center, Hallym University College of Medicine, Anyang, South Korea; ${ }^{10}$ Division of Pulmonary and Critical Care Medicine, Department of Internal Medicine, Chungju Hospital, Konkuk University School of Medicine, Chungju, South Korea

*These authors contributed equally to this work

Correspondence: Hye Yun Park

Division of Pulmonary and Critical Care Medicine, Department of Medicine, Samsung Medical Center. Sungkyunkwan University School of Medicine,

8I Irwon-ro, Gangnam-gu, Seoul 0635I, South Korea $\mathrm{Tel}+82234103429$

Fax +82234103849

Email hyeyunpark@skku.edu

Jung Yeon Lee

Division of Pulmonary and Critical Care Medicine,

Department of Internal Medicine, Chungju

Hospital, Konkuk University School of Medicine,

82 Gukwondae-ro, Chugju-si, Chungcheongbuk-do

27376, South Korea

$\mathrm{Tel}+82438408209$

$\mathrm{Fax}+82438408690$

Email jyl0613@kku.ac.kr
Background: Patients with chronic obstructive pulmonary disease (COPD) often have poor health-related quality of life (HRQoL) that is disproportionate to their degree of airflow limitation. This study evaluated the association between St George's Respiratory Questionnaire for COPD (SGRQ-C) score and forced expiratory volume in one second and investigated the factors responsible for high SGRQ-C score according to severity of airflow limitation.

Methods: Data from 1,264 COPD patients were obtained from the Korean COPD Subgroup Study (KOCOSS) cohort. Patients were categorized into two groups according to severity of airflow limitation: mild-to-moderate and severe-to-very severe COPD groups. We evaluated the clinical factors associated with high SGRQ-C score $(\geq 25)$ in each COPD patient group.

Results: Of the 1,264 COPD patients, 902 (71.4\%) had mild-to-moderate airflow limitation and $362(28.6 \%)$ had severe-to-very severe airflow limitation. Of the mild-to-moderate COPD patients, 59.2\% (534/902) had high SGRQ-C score, while 80.4\% (291/362) of the severe-tovery severe COPD patients had high SGRQ-C score. The association between SGRQ-C score and post-bronchodilator forced expiratory volume in one second (\% predicted) was very weak in the mild-to-moderate COPD patients $(r=-0.103, p=0.002)$ and weak in the severe-to-very severe COPD patients $(r=-0.219, p<0.001)$. Multiple logistic regression analysis revealed that age, being an ex- or current smoker, lower level of education, cough, dyspnea, and number of comorbidities with congestive heart failure, hyperlipidemia, and depression were significantly associated with high SGRQ-C score in mild-to-moderate COPD patients. In comparison, being an ex-smoker and having respiratory symptoms including sputum and dyspnea were significant factors associated with high SGRQ-C score in severe-to-very severe COPD patients.

Conclusions: In addition to the respiratory symptoms of dyspnea and cough, high SGRQ-C score was associated with extra-pulmonary comorbidities in mild-to-moderate COPD patients. However, only respiratory symptoms such as sputum and dyspnea were significantly associated with high SGRQ-C score in severe-to-very severe COPD patients. This indicates the need for an improved management strategy for relieving respiratory symptoms in COPD patients with poor HRQoL. In addition, attention should be paid to extra-pulmonary comorbidities, especially in mild-to-moderate COPD patients with poor HRQoL.

Keywords: chronic obstructive pulmonary disease, morbidity, quality of life

\section{Introduction}

Chronic obstructive pulmonary disease is a growing global health concern affecting over 300 million people worldwide and contributing to $\sim 3$ million deaths every year. ${ }^{1,2}$ It is a chronic lung inflammatory disease that is characterized by persistent and progressive airflow limitation. ${ }^{3}$ In particular, chronic obstructive pulmonary disease (COPD) 
patients with severe airflow limitation often suffer from remarkable respiratory symptoms such as chronic cough, sputum production, breathlessness, and exercise intolerance., ${ }^{4,5}$ Therefore, the substantial symptomatic burden of COPD reduces physical and psychological functioning, ultimately decreasing health-related quality of life (HRQoL). ${ }^{6-10}$

A single measurement of airflow limitation grade often correlates poorly with disease activity, severity, and prognosis, ${ }^{11,12}$ that is potentially limiting in providing an accurate assessment of the complexities of COPD. When assessing COPD patients, the Global Initiative for Chronic Obstructive Lung Disease (GOLD) guidelines suggest including the number of exacerbations over the past 12 months and the severity of symptoms in addition to the degree of airflow limitation. ${ }^{3}$ In order to assess symptom severity, the GOLD guidelines propose two simple measurements: the modified Medical Research Council (mMRC) dyspnea scale and the COPD Assessment Test. ${ }^{13,14}$ The updated GOLD strategy also added the St George's Respiratory Questionnaire (SGRQ) (cut-off point: $\geq 25$ points) and Chronic Respiratory Questionnaire as other methods for grading symptoms. ${ }^{3}$ The SGRQ is the most documented measurement of disease-specific HRQoL ${ }^{15}$ and has been validated in COPD clinical studies. ${ }^{16,17}$ The SGRQ not only allows for comparative measurements of health status among patients, but also helps to quantify changes in health status during clinical follow-up. Therefore, assessing health status is an important additional measurement along with lung function to evaluate disease severity in COPD.

Despite the significant association between impairment of HRQoL measured by the SGRQ and airflow limitation grade, ${ }^{18-21}$ the HRQoL data obtained using the SGRQ were weakly correlated with airflow limitation grade, and there was considerable heterogeneity in HRQoL among COPD patients with the same degree of airflow limitation. Consistent with this finding, mild-to-moderate COPD patients often experience distressing symptoms and poor HRQoL that are disproportionate to their grade of airflow limitation. ${ }^{20}$ However, there is limited information with respect to the factors that affect high SGRQ scores, particularly in mild-to-moderate COPD patients with relatively conserved pulmonary function. In addition, we questioned whether there are factors other than dyspnea that contribute to poor HRQoL in patients with severe-to-very severe COPD. Recently, a COPD-specific version of the St George's Respiratory Questionnaire (SGRQ-C), a shorter version of the SGRQ, was validated specifically for COPD, and it produced scores equivalent to the original SGRQ. ${ }^{22}$ Therefore, the aim of this study was to analyze the distribution of SGRQ-C scores and to identify factors associated with high SGRQ-C score in stable COPD patients according to severity of airflow limitation.

\section{Methods}

\section{Study subjects and data collection}

All subjects were selected from the Korean COPD Subgroup Study (KOCOSS) cohort, which prospectively recruited stable patients at outpatient clinics from 47 referral hospitals in Korea between December 2011 and November 2015. The inclusion criteria for this cohort included the following: a diagnosis of COPD by a pulmonologist; age $\geq 40$ years; symptoms including cough, sputum, and dyspnea; and a post-bronchodilator (BD) forced expiratory volume in one second $\left(\mathrm{FEV}_{1}\right) /$ forced vital capacity $(\mathrm{FVC})<70 \%{ }^{23}$ At enrollment, data including age, sex, height, weight, smoking status, patient-reported education level, area of residence, comorbidities, depression, 6-min walking distance, cough, sputum, mMRC dyspnea score, and SGRQ-C were recorded by physicians or trained nurses using case-report forms. The presence of cough and sputum was defined when the patients answered yes to the questions "Have you ever had a cough for more than 3 months in 1 year?" and "Have you ever had sputum for more than 3 months in 1 year?" The presence of depression was determined based on Beck's Depression Inventory score $\geq 16 .{ }^{24}$ Pulmonary function tests were performed when the patients were stable, and the most recent results obtained within 1 year of enrollment were collected. All of the initial datasets were analyzed to characterize baseline patient characteristics. This study was approved by the Institutional Review Board (IRB) of each hospital (Seoul National University Hospital IRB, Catholic Medical Center Central IRB, Yonsei University Wonju College of Medicine IRB, Severance Hospital IRB, Soonchunhyang University Cheonan Hospital IRB, Ajou University Hospital IRB, Hallym University Dongtan Sacred Heart Hospital IRB, Hallym University Chuncheon Sacred Heart Hospital IRB, Hallym University Pyeongchon Sacred Heart Hospital IRB, Hanyang University Guri Hospital IRB, Konkuk University Hospital IRB, Konkuk University Chungju Hospital IRB, Hallym University Kangdong Sacred Heart Hospital IRB, Hallym University Kangnam Sacred Heart Hospital IRB, Seoul National University Boramae Medical Center IRB, Korea University Guro Hospital IRB, Korea University Anam Hospital IRB, Dongguk University Gyeongju Hospital IRB, Dong-A University Hospital IRB, Gachon University Gil Medical Center IRB, Gangnam Severance Hospital IRB, Kyung Hee 
University Hospital at Gangdong IRB, Kangbuk Samsung Hospital IRB, Kangwon National University Hospital IRB, Kyungpook National University Hospital IRB, Gyeongsang National University Hospital IRB, Pusan National University Hospital IRB, Soonchunhyang University Bucheon Hospital IRB, Seoul National University Bundang Hospital IRB, CHA Bundang Medical Center, CHA University IRB, Asan Medical Center IRB, Inje University Ilsan Paik Hospital IRB, Eulji General Hospital IRB, Samsung Medical Center IRB, Ulsan University Hospital IRB, Soonchunhyang University Seoul Hospital IRB, Yeungnam University Hospital IRB, Ewha Womans University Mokdong Hospital IRB, Inha University Hospital IRB, Chonbuk National University Hospital IRB, and Jeju National University Hospital IRB). All patients provided written informed consent.

Approval to use patients' medical records from each center was obtained, and the confidentiality of patients was maintained.

\section{Pulmonary function tests and severity of airflow limitation}

Spirometry was performed according to the recommendations of the American Thoracic Society/European Respiratory Society criteria. ${ }^{25}$ Absolute values for $\mathrm{FEV}_{1}$ and FVC were obtained, and the percentages of predicted values for $\mathrm{FEV}_{1}$ and $\mathrm{FVC}$ were calculated using the Morris equation. ${ }^{26}$ The severity of airflow limitation was classified according to the GOLD grading system: mild-to-moderate corresponded to post-BD $\mathrm{FEV}_{1} \geq 50 \%$ predicted and severe-to-very severe corresponded to post-BD $\mathrm{FEV}_{1}<50 \%$ predicted. $^{3}$

\section{HRQoL measurement}

The SGRQ-C was administered to assess subjective health status. $^{22}$ The SGRQ-C contains 40 items and provides three component scores for symptoms, activity, and impact, as well as a total score. The total and component scores were calculated according to the algorithms provided in the SGRQ-C instruction manual. High SGRQ-C score and low SGRQ-C score were defined as SGRQ-C score $\geq 25$ and SGRQ-C score $<25$, respectively. ${ }^{3,22}$

\section{Statistical analyses}

For continuous variables, descriptive statistics were reported as the mean and standard deviation, while categorical variables were reported as the number of patients (\%) per category and the frequency of a response. Continuous variables were compared using two-sample $t$-tests, while categorical variables were compared using Chi-square or Fisher's exact tests, as appropriate. The correlation between post-BD FEV (\% predicted) and SGRQ-C was analyzed using Pearson's correlation $(r)$. Strength of association was classified based on the absolute values for $r$ as follows: very weak (0-0.19), weak (0.20-0.39), moderate (0.40-0.59), strong (0.6-0.79), and very strong $(0.80-1.0) .{ }^{27}$ Multiple logistic regression models were generated to identify factors associated with high SGRQ score (SGRQ-C $\geq 25$ ). Based on univariate analysis ( $p$-values $<0.20$, except for area of residence) and clinical relevance, age, sex, body mass index, education, smoking status, cough ( $>3$ months/year), sputum ( $>3$ months/year), dyspnea ( $\geq$ mMRC II), and number of comorbidities were inserted into the logistic model for Model 1. To evaluate the impact of each comorbidity on high SGRQ score, we further adjusted each comorbidity with all of the abovementioned variables in Model 1 except for number of comorbidities. In order to address missing or unknown values, we created a missing value category for each incomplete, independent, and categorical variable. To handle missing data in the regression model, we used the missing-indicator method, which is a popular and simple method for managing missing data in clinical research. ${ }^{28}$ However, since the number of missing data points for the Beck's depression score was relatively large, missing data were removed in the analysis of the odds ratio of Beck's depression score for high SGRQ-C score, and depression was not included in the number of comorbidities. Any $p$-values less than 0.05 were considered statistically significant. Data were analyzed using IBM SPSS Statistics for Windows, version 23.0 (Armonk, NY, USA).

\section{Results}

\section{Study patients}

A total of 1,391 patients with COPD were recruited during the study period. Since the primary aim of this study was to evaluate the potential factors affecting high SGRQ-C score, patients without detailed data regarding comorbidities $(n=127)$ were excluded. Ultimately, 1,264 COPD patients were included in our analysis. Of the enrolled patients, 902 (71.4\%) had mild-to-moderate COPD, and 59.2\% (534/902) of these had high SGRQ-C score. There were 362 (28.6\%) patients with severe-to-very severe COPD, of whom $80.4 \%$ (291/362) had high SGRQ-C score (Figure 1).

\section{Correlation between SGRQ-C and Post-BD FEV (\% predicted) according to severity of airflow limitation}

Among all of the COPD patients enrolled in this study, there was a weak negative correlation between SGRQ-C score and 


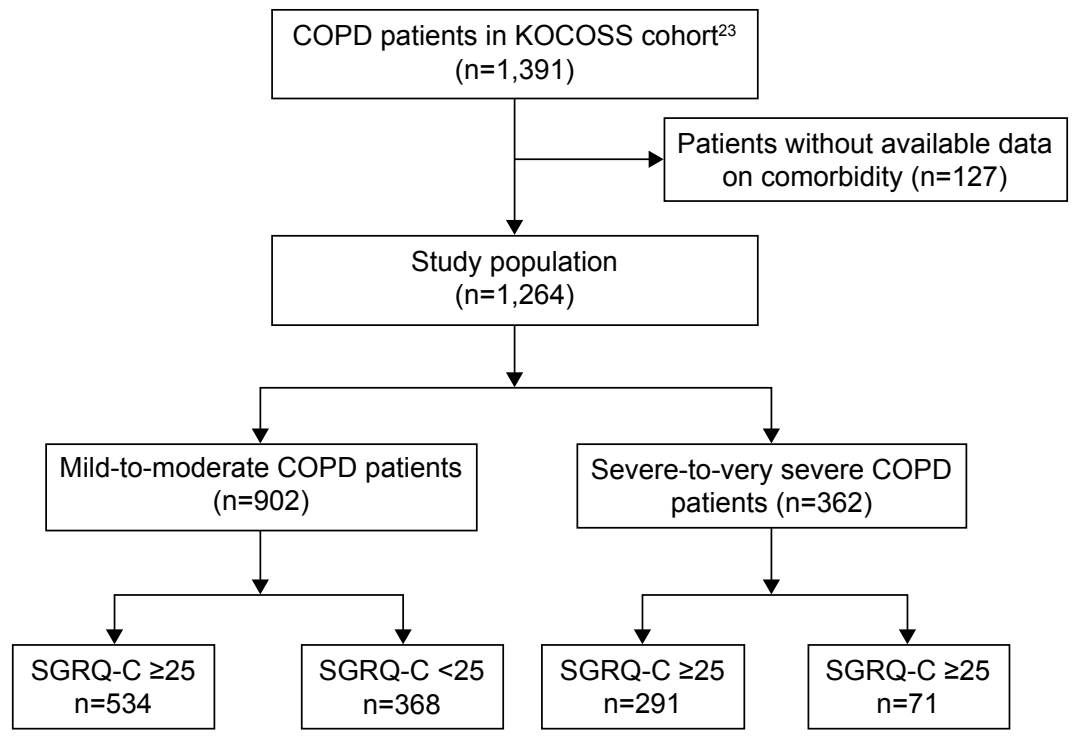

Figure I Flowchart of the study population.

Abbreviations: COPD, chronic obstructive pulmonary disease; KOCOSS, Korean COPD Subgroup Study; SGRQ-C, St George's Respiratory Questionnaire for COPD.

post-BD $\mathrm{FEV}_{1}$ ( $\%$ predicted) $(r=-0.293, p<0.001)$. While only a very weak negative correlation was identified between the SGRQ-C score and post-BD FEV $(\%$ predicted) in mildto-moderate COPD patients ( $r=-0.103, p=0.002$ ) (Figure 2 ), a weak negative correlation between SGRQ-C score and post-BD FEV 1 ( $\%$ predicted $)(r=-0.219, p<0.001)$ was identified in severe-to-very severe COPD patients (Figure 3 ).

\section{Comparison of clinical characteristics in mild-to-moderate COPD patients according to SGRQ-C score}

Among patients with mild-to-moderate COPD, we compared the demographic and clinical characteristics between those with high and low SGRQ-C scores (Table 1). Patients with high SGRQ-C score were more likely to be older $(p=0.001)$ and less educated $(p<0.001)$ compared with those with low SGRQ-C score. In addition, patients with mild-to-moderate COPD with high SGRQ-C score suffered more respiratory symptoms

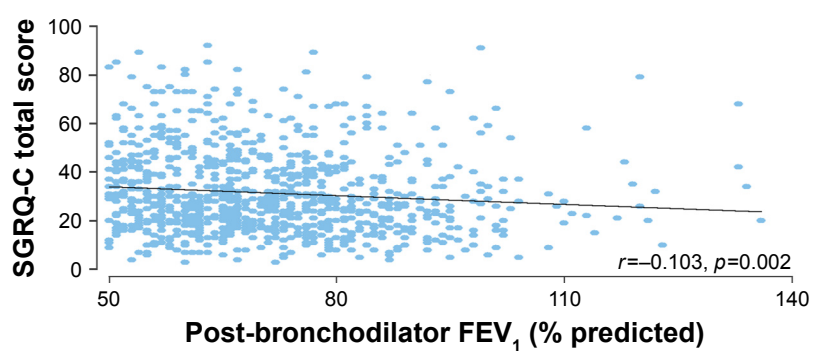

Figure 2 Correlation between SGRQ-C total score and post-BD FEV (\% predicted) in patients with mild-to-moderate COPD.

Abbreviations: BD, bronchodilator; COPD, chronic obstructive pulmonary disease; $\mathrm{FEV}_{\text {, }}$, forced expiratory volume in one second; SGRQ-C, St George's Respiratory Questionnaire for COPD. such as cough $(p<0.001)$, sputum $(p<0.001)$, and dyspnea ( $\geq$ mMRC II) $(p<0.001)$, were less educated $(p<0.001)$, and had more comorbidities $(p=0.002)$ than those with low SGRQ-C score. However, there were no significant differences in sex, body mass index, smoking status, or area of residence between the patients with high SGRQ-C and those with low SGRQ-C.

Compared to patients with low SGRQ-C score, those with high SGRQ-C score were more likely to have extrapulmonary comorbidities such as congestive heart failure ( $p=0.030)$, osteoporosis $(p=0.020)$, gastroesophageal reflux disease $(p=0.017)$, hyperlipidemia $(p=0.008)$, and thyroid disease $(p=0.011)$, as well as a history of pneumonia $(p=0.008)$ and allergic rhinitis $(p=0.001)$. In addition, depressed mood

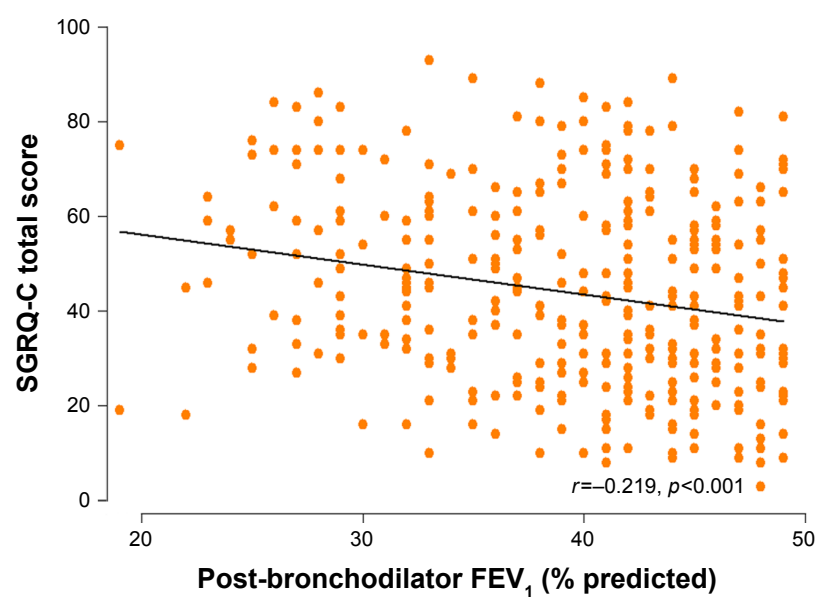

Figure 3 Correlation between SGRQ-C total score and post- BD FEV (\% predicted) in patients with severe-to-very severe COPD.

Abbreviations: $\mathrm{BD}$, bronchodilator; COPD, chronic obstructive pulmonary disease; $\mathrm{FEV}_{1}$, forced expiratory volume in one second; SGRQ-C, St George's Respiratory Questionnaire for COPD. 
Table I Clinical characteristics of mild-to-moderate COPD patients according to SGRQ-C score

\begin{tabular}{|c|c|c|c|c|}
\hline & $\begin{array}{l}\text { Total } \\
(n=902,100 \%)\end{array}$ & $\begin{array}{l}\text { SGRQ-C } \geq 25 \\
(n=534,59.2 \%)\end{array}$ & $\begin{array}{l}\text { SGRQ-C }<25 \\
(n=368,40.8 \%)\end{array}$ & $p$-value \\
\hline Age, years & $69.0 \pm 7.6$ & $69.9 \pm 7.6$ & $67.9 \pm 7.5$ & 0.001 \\
\hline Sex, male & $801(88.8)$ & $467(87.5)$ & $334(90.8)$ & 0.122 \\
\hline Body mass index, $\mathrm{kg} / \mathrm{m}^{2}$ & $23.4 \pm 3.3$ & $23.4 \pm 3.4$ & $23.4 \pm 3.1$ & 0.803 \\
\hline Body mass index $\leq 21 \mathrm{~kg} / \mathrm{m}^{2}$ & $210(23.3)$ & $125(23.4)$ & $85(23.1)$ & 0.914 \\
\hline \multicolumn{5}{|l|}{ Smoking status } \\
\hline Current smoker & $256(28.4)$ & | 48 (27.7) & $108(29.3)$ & \multirow[t]{3}{*}{0.325} \\
\hline Ex-smoker & $538(59.6)$ & $328(6 I .4)$ & $210(57.1)$ & \\
\hline Never smoker & $108(12.0)$ & $58(10.9)$ & $50(13.6)$ & \\
\hline \multicolumn{5}{|l|}{ Education } \\
\hline$\leq$ High school education & $781(86.6)$ & $487(9 \mid .2)$ & $294(79.9)$ & \multirow[t]{2}{*}{$<0.00$ I } \\
\hline$\geq$ College education & $12 \mid(13.4)$ & $47(8.8)$ & $74(20.1)$ & \\
\hline \multicolumn{5}{|l|}{ Area of residence } \\
\hline Large city & $484(53.7)$ & $286(53.6)$ & $198(53.8)$ & \multirow[t]{4}{*}{0.186} \\
\hline Small- and medium-sized cities & $253(28.0)$ & $143(26.8)$ & $110(29.9)$ & \\
\hline Rural area & $160(17.7)$ & $100(18.7)$ & $60(16.3)$ & \\
\hline Other & $5(0.6)$ & $5(0.9)$ & $0(0)$ & \\
\hline \multicolumn{5}{|l|}{ Respiratory symptoms } \\
\hline Cough $^{\mathrm{a}}$ & $203(22.5)$ & $153(28.7)$ & $50(13.6)$ & $<0.001$ \\
\hline Sputum ${ }^{a}$ & $279(30.9)$ & $192(36.0)$ & $87(23.6)$ & $<0.00$ I \\
\hline Dyspnea $(\geq \mathrm{mMRC} I)^{\mathrm{a}}$ & $301(33.4)$ & $245(45.9)$ & $56(15.2)$ & $<0.001$ \\
\hline \multicolumn{5}{|l|}{ Comorbidities $^{\mathrm{a}}$} \\
\hline Number of comorbidities ${ }^{\mathrm{b}}$ & $2(I-3)$ & $2(I-3)$ & $2(I-3)$ & 0.002 \\
\hline Myocardial infarction & $46(5.1)$ & $30(5.6)$ & $16(4.3)$ & 0.114 \\
\hline Congestive heart failure & $31(3.4)$ & $24(4.5)$ & $7(1.9)$ & 0.030 \\
\hline Peripheral vascular disease & $23(2.5)$ & $17(3.2)$ & $6(1.6)$ & 0.113 \\
\hline Diabetes mellitus & $152(16.9)$ & $99(18.5)$ & $53(14.4)$ & 0.242 \\
\hline Hypertension & $376(41.7)$ & $236(44.2)$ & $140(38.0)$ & 0.058 \\
\hline Osteoporosis & $43(4.8)$ & $31(5.8)$ & $12(3.3)$ & 0.020 \\
\hline Gastroesophageal reflux disease & $90(10.0)$ & $60(11.2)$ & $30(8.2)$ & 0.017 \\
\hline Hyperlipidemia & $103(11.4)$ & $71(13.3)$ & $32(8.7)$ & 0.008 \\
\hline Thyroid disease & $22(2.4)$ & $14(2.6)$ & $8(2.2)$ & 0.011 \\
\hline Bronchiectasis & $54(6.0)$ & $34(6.4)$ & $20(5.4)$ & 0.130 \\
\hline Chronic bronchitis & $70(7.8)$ & $42(7.9)$ & $28(7.6)$ & 0.142 \\
\hline Previous history or current status of TB & $211(23.4)$ & $135(25.3)$ & $76(20.7)$ & 0.186 \\
\hline Previous history of pneumonia & $134(14.9)$ & $92(17.2)$ & $42(11.4)$ & 0.008 \\
\hline Asthma & $388(43.0)$ & $219(41.0)$ & $169(45.9)$ & 0.064 \\
\hline Allergic rhinitis & $96(10.6)$ & $67(12.5)$ & $29(7.9)$ & 0.001 \\
\hline Beck's depression inventory score $\geq 16^{\mathrm{c}}$ & $34 / 198(17.2)$ & $22 / 91(24.2)$ & $12 / 107(\mid 1.2)$ & 0.016 \\
\hline 6-min walk distance, $\mathrm{m}$ & $\begin{array}{l}377.1 \pm I \mid 12.7 \\
(n=720)\end{array}$ & $\begin{array}{l}358.9 \pm 107.7 \\
(n=424)\end{array}$ & $\begin{array}{l}403.1 \pm \mid I 4.8 \\
(n=296)\end{array}$ & $<0.001$ \\
\hline
\end{tabular}

Notes: Data are shown as mean $( \pm S D)$ or number $(\%)$. ${ }^{a}$ The numbers of missing/unknown data are as follows: cough $(n=10)$, sputum $(n=12)$, myocardial infarction $(n=38)$, congestive heart failure $(n=38)$, peripheral vascular disease $(n=43)$, diabetes mellitus $(n=8)$, hypertension $(n=7)$, osteoporosis $(n=31)$, gastroesophageal reflux disease $(n=42)$, hyperlipidemia $(n=46)$, thyroid disease $(n=39)$, bronchiectasis $(n=97)$, chronic bronchitis $(n=106)$, previous history or current status of TB ( $n=29)$, previous history of pneumonia $(n=51)$, asthma $(n=43)$, and allergic rhinitis $(n=39)$. 'bepression was not included in the number of comorbidities. ' ${ }^{\circ}$ valuated in 198 patients.

Abbreviations: COPD, chronic obstructive pulmonary disease; mMRC, modified Medical Research Council; SGRQ-C, St George's Respiratory Questionnaire for COPD; $\mathrm{SD}$, standard deviation; TB, tuberculosis.

was more frequent in patients with high SGRQ-C score than in those with low SGRQ-C score $(p=0.016)$. However, Beck's Depression Inventory was performed only for 198 patients $(22.0 \%)$.

Patients with mild-to-moderate COPD with high SGRQ-C score had a significantly lower level of functional exercise capacity (as estimated by the 6-min walk distance $[p<0.001]$ ) compared to patients with low SGRQ-C score.

\section{Comparison of clinical characteristics in severe-to-very severe COPD patients according to HRQoL}

In patients with severe-to-very severe COPD, those with high SGRQ-C score were more likely to have lower body mass index $(p=0.031)$ and respiratory symptoms such as cough $(p=0.014)$, sputum $(p<0.001)$, and dyspnea ( $\geq$ mMRC II) $(p<0.001)$ than those with low SGRQ-C score. 
However, there were no other significant differences between the groups regarding age, sex, smoking status, education, area of residence, or number of comorbidities (Table 2). Compared to patients with low SGRQ-C score, those with high SGRQ-C score were more likely to have osteoporosis $(p=0.023)$ and a history of pneumonia $(p=0.003)$. Similar to the findings in mild-to-moderate COPD patients, patients with severe-to-very severe COPD with high SGRQ-C score had a significantly shorter 6-min walk distance $(p<0.001)$ than those with low SGRQ-C score.

\section{Factors affecting high SGRQ-C score according to severity of airflow limitation}

In order to evaluate the independent factors affecting high SGRQ-C score, multiple logistic regression analysis was performed for each COPD patient group (Tables 3 and 4).

Table 2 Clinical characteristics of severe-to-very severe COPD patients according to SGRQ-C score

\begin{tabular}{|c|c|c|c|c|}
\hline & $\begin{array}{l}\text { Total } \\
(n=362,100 \%)\end{array}$ & $\begin{array}{l}\text { SGRQ-C } \geq 25 \\
(n=291,80.4 \%)\end{array}$ & $\begin{array}{l}\text { SGRQ-C }<25 \\
(n=71,19.6 \%)\end{array}$ & $p$-value \\
\hline Age, years & $68.0 \pm 7.9$ & $68.4 \pm 8.2$ & $66.7 \pm 6.6$ & 0.055 \\
\hline Sex, male & $347(95.9)$ & $278(95.5)$ & $69(97.2)$ & 0.745 \\
\hline Body mass index, $\mathrm{kg} / \mathrm{m}^{2}$ & $21.5 \pm 3.3$ & $21.4 \pm 3.3$ & $21.8 \pm 2.9$ & 0.282 \\
\hline Body mass index $\leq 21 \mathrm{~kg} / \mathrm{m}^{2}$ & I74 (48.I) & $148(50.9)$ & $26(36.6)$ & 0.031 \\
\hline \multicolumn{5}{|l|}{ Smoking status } \\
\hline Current smoker & $82(22.7)$ & $64(22.0)$ & I8 (25.3) & \multirow[t]{3}{*}{0.051} \\
\hline Ex-smoker & $256(70.7)$ & $212(72.9)$ & $44(62.0)$ & \\
\hline Never smoker & $24(6.6)$ & I5 (5.I) & $9(12.7)$ & \\
\hline \multicolumn{5}{|l|}{ Education } \\
\hline$\leq$ High school education & $321(88.7)$ & $258(88.7)$ & $63(88.7)$ & \multirow[t]{2}{*}{0.986} \\
\hline$\geq$ College education & $4 \mid(I I .3)$ & $33(11.3)$ & $8(11.3)$ & \\
\hline \multicolumn{5}{|l|}{ Area of residence } \\
\hline Large city & $162(44.8)$ & $128(44.0)$ & $34(47.9)$ & \multirow[t]{4}{*}{0.513} \\
\hline Small- and medium-sized cities & $140(38.7)$ & $112(38.5)$ & $28(39.4)$ & \\
\hline Rural area & $57(15.7)$ & $49(16.8)$ & $8(11.3)$ & \\
\hline Other & $3(0.8)$ & $2(0.7)$ & I (I.4) & \\
\hline \multicolumn{5}{|l|}{ Respiratory symptoms } \\
\hline Cough $^{\mathrm{a}}$ & $98(27.1)$ & $88(30.2)$ & $10(14.1)$ & 0.014 \\
\hline Sputum $^{\mathrm{a}}$ & $120(33.1)$ & $110(37.8)$ & $10(14.1)$ & $<0.00$ I \\
\hline Dyspnea $(\geq \mathrm{mMRC} \text { II) })^{\mathrm{a}}$ & $220(60.8)$ & $201(69.1)$ & $19(26.8)$ & $<0.00 \mathrm{I}$ \\
\hline \multicolumn{5}{|l|}{ Comorbidities $^{\mathrm{a}}$} \\
\hline Number of comorbidities ${ }^{b}$ & $2(I-3)$ & $2(I-3)$ & $2(I-3)$ & 0.298 \\
\hline Myocardial infarction & $20(5.5)$ & I5 (5.2) & $5(7.0)$ & 0.304 \\
\hline Congestive heart failure & $17(4.7)$ & $13(4.5)$ & $4(5.6)$ & 0.234 \\
\hline Peripheral vascular disease & $9(2.5)$ & $8(2.7)$ & I (I.4) & 0.205 \\
\hline Diabetes mellitus & $66(18.2)$ & $53(18.2)$ & $13(18.3)$ & 1.000 \\
\hline Hypertension & $127(35.1)$ & $96(33.0)$ & $31(43.7)$ & 0.178 \\
\hline Osteoporosis & $16(4.4)$ & $16(5.5)$ & $0(0)$ & 0.023 \\
\hline Gastroesophageal reflux disease & $30(8.3)$ & $25(8.6)$ & $5(7.0)$ & 0.362 \\
\hline Hyperlipidemia & $24(6.6)$ & $19(6.5)$ & $5(7.0)$ & 0.544 \\
\hline Thyroid disease & $3(0.8)$ & $2(0.7)$ & $\mathrm{I}(\mathrm{I} .4)$ & 0.265 \\
\hline Bronchiectasis & $32(8.8)$ & $25(8.6)$ & $7(9.9)$ & 0.167 \\
\hline Chronic bronchitis & $27(7.5)$ & $26(8.9)$ & $\mathrm{I}(\mathrm{I} .4)$ & 0.073 \\
\hline Previous history or current status of TB & $107(29.6)$ & $90(30.9)$ & $17(23.9)$ & 0.057 \\
\hline Previous history of pneumonia & $64(17.7)$ & $58(19.9)$ & $6(8.5)$ & 0.003 \\
\hline Asthma & $172(47.5)$ & $137(47.1)$ & $35(49.3)$ & 0.077 \\
\hline Allergic rhinitis & $38(10.5)$ & $30(10.3)$ & $8(11.3)$ & 0.171 \\
\hline Beck's depression inventory score $\geq 16^{c}$ & $21 / 124(16.9)$ & $17 / 87(19.5)$ & $4 / 37(10.8)$ & 0.236 \\
\hline 6-min walk distance, $\mathrm{m}$ & $\begin{array}{l}336.3 \pm 119.0 \\
(n=264)\end{array}$ & $\begin{array}{l}320.9 \pm 119.3 \\
(n=21 I)\end{array}$ & $\begin{array}{l}397.1 \pm 97.3 \\
(n=53)\end{array}$ & $<0.001$ \\
\hline
\end{tabular}

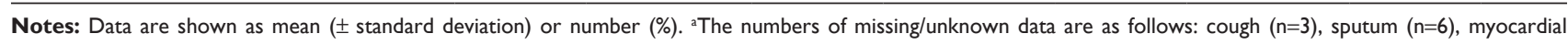
infarction $(n=10)$, congestive heart failure $(n=11)$, peripheral vascular disease $(n=\mid I)$, diabetes mellitus $(n=2)$, hypertension $(n=5)$, osteoporosis $(n=10)$, gastroesophageal reflux disease $(n=9)$, hyperlipidemia $(n=8)$, thyroid disease $(n=8)$, bronchiectasis $(n=22)$, chronic bronchitis $(n=26)$, previous history or current status of TB ( $n=14)$, previous history of pneumonia $(n=16)$, asthma $(n=18)$, and allergic rhinitis $(n=14)$. 'Depression was not included in the number of comorbidities. ' ${ }^{\mathrm{C}}$ Evaluated in I24 patients.

Abbreviations: COPD, chronic obstructive pulmonary disease; mMRC, modified Medical Research Council; SGRQ-C, St George's Respiratory Questionnaire for COPD; $\mathrm{TB}$, tuberculosis. 
Table 3 Multivariate logistic regression analysis of the factors associated with high SGRQ-C score (SGRQ-C score $\geq 25$ ) in mild-to-moderate COPD patients

\begin{tabular}{|c|c|c|}
\hline & $\begin{array}{l}\text { Adjusted OR } \\
(95 \% \mathrm{Cl})\end{array}$ & $p$-value \\
\hline \multicolumn{3}{|l|}{ Model I } \\
\hline Age, years & $1.02(1.001-1.04)$ & 0.040 \\
\hline Sex, male & $0.57(0.31-1.06)$ & 0.076 \\
\hline Body mass index $\leq 21 \mathrm{~kg} / \mathrm{m}^{2}$ & $0.99(0.70-1.42)$ & 0.973 \\
\hline \multicolumn{3}{|l|}{ Smoking status } \\
\hline Never smoker & Reference & - \\
\hline Ex-smoker & $2.01(1.01-3.70)$ & 0.024 \\
\hline Current smoker & $2.0 \mathrm{I}(\mathrm{I} .06-3.8 \mathrm{I})$ & 0.033 \\
\hline Education $\leq$ high school education & $2.51(1.61-3.89)$ & $<0.001$ \\
\hline Cough $^{\mathrm{a}}$ & $2.21(1.43-3.42)$ & $<0.001$ \\
\hline Sputum ${ }^{\mathrm{a}}$ & $1.16(0.80-1.68)$ & 0.447 \\
\hline Dyspnea $(\geq \mathrm{mMRC} \text { II) })^{\mathrm{a}}$ & $4.06(2.87-5.73)$ & $<0.001$ \\
\hline Number of comorbidities ${ }^{b}$ & $1.19(1.07-1.32)$ & 0.001 \\
\hline \multicolumn{3}{|l|}{ Model 2} \\
\hline \multicolumn{3}{|l|}{ Comorbidity ${ }^{\mathrm{a}}$} \\
\hline Myocardial infarction & $1.35(0.68-2.69)$ & 0.388 \\
\hline Congestive heart failure & $2.81(1.14-6.95)$ & 0.025 \\
\hline Peripheral vascular disease & $1.85(0.69-5.02)$ & 0.224 \\
\hline Diabetes mellitus & $1.46(0.98-2.17)$ & 0.061 \\
\hline Hypertension & $1.33(0.98-1.79)$ & 0.066 \\
\hline Osteoporosis & $1.22(0.57-2.59)$ & 0.610 \\
\hline Gastroesophageal reflux disease & $1.46(0.88-2.44)$ & 0.148 \\
\hline Hyperlipidemia & $1.77(1.10-2.87)$ & 0.020 \\
\hline Thyroid disease & $0.96(0.36-2.54)$ & 0.927 \\
\hline Bronchiectasis & $1.32(0.70-2.52)$ & 0.391 \\
\hline Chronic bronchitis & $0.95(0.55-1.66)$ & 0.860 \\
\hline Previous history or current status of TB & $1.24(0.87-1.78)$ & 0.229 \\
\hline Previous history of pneumonia & $1.46(0.94-2.26)$ & 0.092 \\
\hline Asthma & $0.97(0.72-1.31)$ & 0.843 \\
\hline Allergic rhinitis & $1.36(0.80-2.30)$ & 0.251 \\
\hline Beck's depression inventory score $\geq 16^{\mathrm{c}}$ & $2.39(1.02-5.59)$ & 0.045 \\
\hline
\end{tabular}

Notes: Model I was adjusted for age, sex, body mass index, education, smoking status, cough, sputum, dyspnea, and number of comorbidities. Model 2 was adjusted for each comorbidity with all of the abovementioned variables in Model I except for number of comorbidities. ${ }^{a}$ The numbers of missing/unknown data are as follows: cough $(n=10)$, sputum $(n=12)$, myocardial infarction $(n=38)$, congestive heart failure $(n=38)$, peripheral vascular disease $(n=43)$, diabetes mellitus $(n=8)$, hypertension $(n=7)$, osteoporosis $(n=31)$, gastroesophageal reflux disease $(n=42)$, hyperlipidemia $(n=46)$, thyroid disease $(n=39)$, bronchiectasis $(n=97)$, chronic bronchitis $(n=106)$, previous history or current status of TB $(n=29)$, previous history of pneumonia $(n=51)$, asthma $(n=43)$, and allergic rhinitis $(n=39)$. ${ }^{\text {bDepression was not included in the number of comorbidities. ' } E v a l u a t e d}$ in 198 patients.

Abbreviations: COPD, chronic obstructive pulmonary disease; mMRC, modified Medical Research Council; OR, odds ratio; SGRQ-C, St George's Respiratory Questionnaire for COPD; TB, tuberculosis.

In mild-to-moderate COPD patients, age (adjusted OR $[\mathrm{aOR}]=1.02, p=0.040)$, ex-smoker $(\mathrm{aOR}=2.01, p=0.024)$, current smoker $(\mathrm{aOR}=2.01, p=0.033)$, lower level of education ( $\leq$ high school education, aOR $=2.51, p<0.001$ ), cough $(\mathrm{aOR}=2.21, p<0.001)$, higher dyspnea scale $(\geq \mathrm{mMRC}$ II, $\mathrm{aOR}=4.06, p<0.001)$, and number of comorbidities (aOR $=1.19, p=0.001)$ were significantly associated with high SGRQ-C score (Model 1 in Table 3). With regard to comorbidities, congestive heart failure $(\mathrm{aOR}=2.81, p=0.025)$,
Table 4 Multivariate logistic regression analysis of the factors associated with high SGRQ-C score (SGRQ-C score $\geq 25$ ) in severe-to-very severe COPD patients

\begin{tabular}{|c|c|c|}
\hline & $\begin{array}{l}\text { Adjusted OR } \\
(95 \% \mathrm{Cl})\end{array}$ & $p$-value \\
\hline \multicolumn{3}{|l|}{ Model I } \\
\hline Age, years & I.0I (0.98-1.05) & 0.490 \\
\hline Sex & $0.49(0.08-2.93)$ & 0.434 \\
\hline Body mass index $\leq 21 \mathrm{~kg} / \mathrm{m}^{2}$ & $1.61(0.87-2.99)$ & 0.127 \\
\hline \multicolumn{3}{|l|}{ Smoking status } \\
\hline Never smoker & Reference & - \\
\hline Ex-smoker & $4.76(1.54-14.77)$ & 0.007 \\
\hline Current smoker & $2.57(0.77-8.62)$ & 0.126 \\
\hline Education $\leq$ high school education & $1.19(0.47-3.01)$ & 0.714 \\
\hline Cough $^{\mathrm{a}}$ & $1.49(0.58-3.83)$ & 0.407 \\
\hline Sputum ${ }^{a}$ & $2.87(1.18-6.99)$ & 0.021 \\
\hline Dyspnea ( $\geq$ mMRC II) & $4.92(2.67-9.06)$ & $<0.001$ \\
\hline Number of comorbidities ${ }^{b}$ & $1.00(0.82-1.23)$ & 0.978 \\
\hline \multicolumn{3}{|l|}{ Model 2} \\
\hline \multicolumn{3}{|l|}{ Comorbidity ${ }^{a}$} \\
\hline Myocardial infarction & $0.64(0.20-1.99)$ & 0.437 \\
\hline Congestive heart failure & $0.81(0.23-2.83)$ & $0.74 I$ \\
\hline Peripheral vascular disease & $3.00(0.32-27.78)$ & 0.334 \\
\hline Diabetes mellitus & $0.83(0.37-1.83)$ & 0.639 \\
\hline Hypertension & $0.70(0.38-1.29)$ & 0.250 \\
\hline Osteoporosis & NA & NA \\
\hline Gastroesophageal reflux disease & $\mathrm{I} .65(0.50-5.47)$ & $0.41 \mathrm{I}$ \\
\hline Hyperlipidemia & $0.98(0.29-3.29)$ & 0.975 \\
\hline Thyroid disease & $0.47(0.03-7.5 \mathrm{I})$ & 0.591 \\
\hline Bronchiectasis & $\mathrm{I} .0 \mathrm{I}(0.36-2.8 \mathrm{I})$ & 0.988 \\
\hline Chronic bronchitis & $3.96(0.46-34.42)$ & 0.213 \\
\hline Previous history or current status of TB & $1.39(0.68-2.83)$ & 0.363 \\
\hline Previous history of pneumonia & $2.23(0.84-5.91)$ & 0.108 \\
\hline Asthma & $0.97(0.53-1.77)$ & 0.910 \\
\hline Allergic rhinitis & $0.79(0.30-2.06)$ & 0.625 \\
\hline Beck's depression inventory score $\geq 16^{c}$ & $1.59(0.42-6.00)$ & 0.496 \\
\hline
\end{tabular}

Notes: Model I was adjusted for age, sex, body mass index, education, smoking status, cough, sputum, dyspnea, and number of comorbidities. Model 2 was adjusted for each comorbidity with all of the abovementioned variables in Model I except for number of comorbidities. ${ }^{a}$ The numbers of missing/unknown data are as follows: cough $(n=3)$, sputum $(n=6)$, myocardial infarction $(n=10)$, congestive heart failure $(n=11)$, peripheral vascular disease $(n=I I)$, diabetes mellitus $(n=2)$, hypertension $(n=5)$, osteoporosis $(n=10)$, gastroesophageal reflux disease $(n=9)$, hyperlipidemia $(n=8)$, thyroid disease $(n=8)$, bronchiectasis $(n=22)$, chronic bronchitis $(n=26)$, previous history or current status of TB $(n=14)$, previous history of pneumonia $(n=16)$, asthma $(n=18)$, and allergic rhinitis $(n=14)$. ${ }^{\circ}$ Depression was not included in the number of comorbidities. 'Evaluated in 124 patients.

Abbreviations: COPD, chronic obstructive pulmonary disease; mMRC, modified Medical Research Council; OR, odds ratio; SGRQ-C, St George's Respiratory Questionnaire for COPD; TB, tuberculosis.

hyperlipidemia $(\mathrm{aOR}=1.77, p=0.020$ ), and depression (aOR $=2.39, p=0.045)$ were significantly associated with high SGRQ-C score (Model 2 in Table 3).

However, in severe-to-very severe COPD patients, exsmoker $(\mathrm{aOR}=4.76, p=0.007)$, sputum $(\mathrm{aOR}=2.87, p=0.021)$, and higher dyspnea scale $(\geq \mathrm{mMRC}$ II, aOR $=4.92, p<0.001$ ) (Model 1 in Table 4) were significantly associated with high SGRQ-C score, while no comorbidities were associated with high SGRQ-C score. 


\section{Discussion}

In this study, there was a negative correlation between HRQoL and severity of airflow limitation in patients with both mild-to-moderate and severe-to-very severe COPD. As expected, most of the patients with severe-to-very severe COPD (80.4\%) had high SGRQ-C score. In addition, 60\% of patients with mild-to-moderate COPD had high SGRQ-C score, despite having relatively good pulmonary function. The strongest factor affecting high SGRQ-C score was respiratory symptoms, especially dyspnea, regardless of severity of airflow limitation. In addition, both mild-to-moderate and severe-to-very severe COPD patients with high SGRQ-C score were more likely to have poor functional exercise capacity as measured by the 6-min walk test. Aside from dyspnea, other independent factors affecting high SGRQ-C score varied according to severity of airflow limitation. In mild-to-moderate COPD patients, age, being an ex- or current smoker, lower level of education, respiratory symptoms including cough, and number of comorbidities were significant factors associated with high SGRQ-C score. Among the comorbidities, congestive heart failure, hyperlipidemia, and depressed mood were significantly associated with high SGRQ-C score even after adjustment for all relevant covariates including dyspnea. However, in severeto-very severe COPD patients, no comorbidities were associated with high SGRQ-C score, while being an ex-smoker and having respiratory symptoms including sputum remained significant after adjusting for other covariates.

Respiratory symptoms, particularly dyspnea, are key presentations of COPD. Indeed, dyspnea was the most significant factor associated with high SGRQ-C score in COPD patients irrespective of severity of airflow limitation in our study. Additionally, we showed that cough and sputum were also associated with high SGRQ-C score in mild-to-moderate and severe-to-very severe COPD patients, respectively. These findings indicate that relieving respiratory symptoms might be the cornerstone to improving HRQoL in patients with COPD. Regarding functional exercise capacity, previous studies reported that there was an inverse correlation between the 6-min walk distance and severity of COPD or HRQoL measured by SGRQ. ${ }^{21,29}$ The present study further found that the 6-min walk distance was significantly shorter in COPD patients with high SGRQ-C score than in those without high SGRQ-C score even within a similar grade of COPD, suggesting that functional exercise capacity, as measured by the 6-min walk test, was closely associated with HRQoL irrespective of severity of airflow limitation.

This study showed that several comorbidities were significantly associated with poor HRQoL. The presence of comorbidities not only restricts daily physical activity but it is also associated with increased exacerbations and mortality. ${ }^{30-33}$ Several studies, which evaluated the predictive factors for death after an acute COPD exacerbation, found that comorbidities were independently associated with poor outcomes (in addition to other factors including old age, lower body mass index, and previous exacerbation). ${ }^{34,35}$ In addition, comorbidities are associated with increased systemic inflammation, which can eventually worsen morbidities arising from COPD. ${ }^{36,37}$ Consistently, comorbidities alone have the ability to affect HRQoL in COPD patients. ${ }^{38}$ The number of comorbidities has been reported to influence HRQoL in COPD patients, ${ }^{20}$ and a previous report has shown that the presence of a comorbidity affected HRQoL, especially in mild COPD ${ }^{39}$ We also showed that the number of comorbidities was significantly associated with high SGRQ-C score in mild-to-moderate COPD patients, but not in severe-to-very severe COPD patients.

Our data further demonstrated that comorbidities affecting poor HRQoL differed according to severity of airflow limitation in COPD, extending the findings of the ECLIPSE study which reported that comorbidities were heterogeneous according to disease severity in COPD. ${ }^{12}$ In particular, we showed that HRQoL in mild-to-moderate COPD patients was affected by extra-pulmonary comorbidities, among which congestive heart failure, hyperlipidemia, and depression were important contributors to HRQoL impairment as measured by the SGRQ-C. Given that comorbidities are controllable factors, our data provide additional insight into the importance of evaluating extra-pulmonary comorbidities in mild-to-moderate COPD patients with relatively conserved pulmonary function, especially in those with poor HRQoL.

Although extra-pulmonary comorbidities are prevalent in COPD patients, we demonstrated that severe-to-very severe COPD patients had worse HRQoL in the presence of respiratory-related comorbidities, such as a history of pneumonia, compared to patients without such a respiratory history. However, the significance disappeared after adjusting for clinically relevant factors, especially dyspnea, indicating that HRQoL impairment is more significantly influenced by dyspnea than other factors in severe-to-very severe COPD patients.

Interestingly, we found that being an ex-smoker was significantly associated with a high SGRQ-C score in mildto-moderate and severe-to-very severe COPD patients. Although the reason for this association is not clear, it is possible that patients with a high SGRQ-C score had a tendency toward cessation of smoking due to more severe respiratory symptoms such as cough, sputum, and dyspnea. 
This study has several limitations. First, because the KOCOSS cohort study was non-interventional and observational in nature, it is unclear whether the patients' comorbidities were well controlled during the study. Second, the data were obtained from the cross-sectional KOCOSS cohort; therefore, the directionality of the relationship between poor HRQoL and comorbidities is uncertain. Further clinical studies with longitudinal follow-up are needed to confirm our observations. Third, we used the SGRQ-C and did not include any generic instrument to measure the impact of comorbidities on HRQoL. Previous studies found that generic instruments are more sensitive in assessing the impact of comorbidities on HRQoL among COPD patients, especially those with low levels of comorbidity. ${ }^{40,41}$ Further studies using both disease-specific and generic instruments are necessary to confirm the study findings. Finally, the COPD patients in our study were recruited from referral hospitals in Korea. Moreover, the prevalence of certain comorbidities in Korean COPD patients is different from those in Western countries. In particular, there are more individuals with tuberculosis or a history of tuberculosis among Korean COPD patients compared to Western countries. ${ }^{42,43}$ Thus, the results of the study might not be generalizable to populations in other settings including primary care clinics managed by general physicians, or in other countries.

\section{Conclusion}

In conclusion, there was a weak negative correlation between SGRQ-C score and lung function. Respiratory symptoms, especially dyspnea, were significant factors associated with high SGRQ-C score in COPD patients. In addition to dyspnea, the number of comorbidities or extra-pulmonary comorbidities was also associated with high SGRQ-C score in mild-to-moderate COPD patients. This suggests that dyspnea is a powerful factor influencing poor HRQoL in COPD, and that the presence of extra-pulmonary comorbidities should be taken into account in mild-to-moderate COPD patients with poor HRQoL.

\section{Acknowledgments}

HY Park and JY Lee contributed equally to this work. We would like to thank Dr Hyun Il Gil for his support during our research. This study was supported by the Samsung Medical Center Foundation for Medical Research (SMX1151371). Trial registration No NCT02800499. Retrospectively registered June 4, 2016.

\section{Disclosure}

Hye Yun Park received lecture fees from AstraZeneca, Novartis, and Boehringer-Ingelheim. The authors report no other conflicts of interest in this work.

\section{References}

1. Vos T, Flaxman AD, Naghavi M, et al. Years lived with disability (YLDs) for 1160 sequelae of 289 diseases and injuries 1990-2010: a systematic analysis for the Global Burden of Disease Study 2010. Lancet. 2012;380(9859):2163-2196.

2. Lopez-Campos JL, Tan W, Soriano JB. Global burden of COPD. Respirology. 2016;21(1):14-23.

3. GOLD. Global strategy for the diagnosis, management and prevention of chronic obstructive pulmonary disease; 2017. Available from: www. goldcopd.org. Accessed April 15, 2017.

4. Killian KJ, Leblanc P, Martin DH, Summers E, Jones NL, Campbell EJ. Exercise capacity and ventilatory, circulatory, and symptom limitation in patients with chronic airflow limitation. Am Rev Respir Dis. 1992; 146(4):935-940.

5. Viegi G, Pistelli F, Sherrill DL, Maio S, Baldacci S, Carrozzi L. Definition, epidemiology and natural history of COPD. Eur Respir J. 2007;30(5):993-1013.

6. Cooper $\mathrm{CB}$. The connection between chronic obstructive pulmonary disease symptoms and hyperinflation and its impact on exercise and function. Am J Med. 2006;119(10 Suppl 1):21-31.

7. Hartman JE, Boezen HM, de Greef MH, Ten Hacken NH. Physical and psychosocial factors associated with physical activity in patients with chronic obstructive pulmonary disease. Arch Phys Med Rehabil. 2013;94(12):2396-2402.e2397.

8. Kim KU, Park HK, Jung HY, et al. Association of depression with disease severity in patients with chronic obstructive pulmonary disease. Lung. 2014;192(2):243-249.

9. Miravitlles M, Molina J, Naberan K, Cots JM, Ros F, Llor C. Factors determining the quality of life of patients with COPD in primary care. Ther Adv Respir Dis. 2007;1(2):85-92.

10. Henoch I, Strang S, Lofdahl CG, Ekberg-Jansson A. Health-related quality of life in a nationwide cohort of patients with COPD related to other characteristics. Eur Clin Respir J. 2016;3(1):31459.

11. Vestbo J, Rennard S. Chronic obstructive pulmonary disease biomarker(s) for disease activity needed-urgently. Am J Respir Crit Care Med. 2010;182(7):863-864.

12. Agusti A, Calverley PM, Celli B, et al. Characterisation of COPD heterogeneity in the ECLIPSE cohort. Respir Res. 2010;11:122.

13. Bestall JC, Paul EA, Garrod R, Garnham R, Jones PW, Wedzicha JA. Usefulness of the Medical Research Council (MRC) dyspnoea scale as a measure of disability in patients with chronic obstructive pulmonary disease. Thorax. 1999;54(7):581-586.

14. Jones PW, Harding G, Berry P, Wiklund I, Chen WH, Kline Leidy N. Development and first validation of the COPD Assessment Test. Eur Respir J. 2009;34(3):648-654.

15. Jones PW, Quirk FH, Baveystock CM, Littlejohns P. A self-complete measure of health status for chronic airflow limitation. The St. George's Respiratory Questionnaire. Am Rev Respir Dis. 1992;145(6): 1321-1327.

16. Calverley PM, Anderson JA, Celli B, et al. Salmeterol and fluticasone propionate and survival in chronic obstructive pulmonary disease. N Engl J Med. 2007;356(8):775-789.

17. Tashkin DP, Celli B, Senn S, et al. A 4-year trial of tiotropium in chronic obstructive pulmonary disease. N Engl J Med. 2008;359(15): 1543-1554.

18. Antonelli-Incalzi R, Imperiale C, Bellia V, et al. Do GOLD stages of COPD severity really correspond to differences in health status? Eur Respir J. 2003;22(3):444-449.

19. Jones PW. Health status and the spiral of decline. COPD. 2009;6(1): 59-63.

20. Jones PW, Brusselle G, Dal Negro RW, et al. Health-related quality of life in patients by COPD severity within primary care in Europe. Respir Med. 2011;105(1):57-66.

21. Agrawal SR, Joshi R, Jain A. Correlation of severity of chronic obstructive pulmonary disease with health-related quality of life and sixminute walk test in a rural hospital of central India. Lung India. 2015; 32(3):233-240. 
22. Meguro M, Barley EA, Spencer S, Jones PW. Development and validation of an improved, COPD-specific version of the St. George respiratory questionnaire. Chest. 2007;132(2):456-463.

23. Lee JY, Chon GR, Rhee CK, et al. Characteristics of patients with chronic obstructive pulmonary disease at the first visit to a pulmonary medical center in Korea: the Korea COPD Subgroup Study Team Cohort. J Korean Med Sci. 2016;31(4):553-560.

24. Huffman JC, Doughty CT, Januzzi JL, Pirl WF, Smith FA, Fricchione GL. Screening for major depression in post-myocardial infarction patients: operating characteristics of the Beck Depression Inventory-II. Int J Psychiatry Med. 2010;40(2):187-197.

25. Miller MR, Hankinson J, Brusasco V, et al. Standardisation of spirometry. Eur Respir J. 2005;26(2):319-338.

26. Morris JF, Koski A, Johnson LC. Spirometric standards for healthy nonsmoking adults. Am Rev Respir Dis. 1971;103(1):57-67.

27. Resources for Online and Print Readers. Correlation and Regression. Available from: http://www.bmj.com/about-bmj/resources-readers/ publications/statistics-square-one/11-correlation-and-regression. Accessed April 15, 2017.

28. Jones MP. Indicator and stratification methods for missing explanatory variables in multiple linear regression. J Am Statist Assoc. 1996; 91(443):222-230.

29. Nishiyama O, Taniguchi $\mathrm{H}$, Kondoh $\mathrm{Y}$, et al. The effectiveness of the visual analogue scale 8 in measuring health-related quality of life for COPD patients. Respir Med. 2000;94(12):1192-1199.

30. Sievi NA, Senn O, Brack T, et al. Impact of comorbidities on physical activity in COPD. Respirology. 2015;20(3):413-418.

31. Hurst JR, Vestbo J, Anzueto A, et al. Susceptibility to exacerbation in chronic obstructive pulmonary disease. $N$ Engl J Med. 2010;363(12): 1128-1138.

32. Anthonisen NR, Connett JE, Enright PL, Manfreda J; Lung Health Study Research G. Hospitalizations and mortality in the Lung Health Study. Am J Respir Crit Care Med. 2002;166(3):333-339.

33. Sin DD, Anthonisen NR, Soriano JB, Agusti AG. Mortality in COPD: role of comorbidities. Eur Respir J. 2006;28(6):1245-1257.
34. Piquet J, Chavaillon JM, David P, Martin F, Blanchon F, Roche N. High-risk patients following hospitalisation for an acute exacerbation of COPD. Eur Respir J. 2013;42(4):946-955.

35. Singanayagam A, Schembri S, Chalmers JD. Predictors of mortality in hospitalized adults with acute exacerbation of chronic obstructive pulmonary disease. Ann Am Thorac Soc. 2013;10(2):81-89.

36. Miller J, Edwards LD, Agusti A, et al. Comorbidity, systemic inflammation and outcomes in the ECLIPSE cohort. Respir Med. 2013; 107(9):1376-1384.

37. Barnes PJ, Celli BR. Systemic manifestations and comorbidities of COPD. Eur Respir J. 2009;33(5):1165-1185.

38. Sundh J, Johansson G, Larsson K, et al. Comorbidity and health-related quality of life in patients with severe chronic obstructive pulmonary disease attending Swedish secondary care units. Int J Chron Obstruct Pulmon Dis. 2015;10:173-183.

39. Ferrer M, Alonso J, Morera J, et al. Chronic obstructive pulmonary disease stage and health-related quality of life. The Quality of Life of Chronic Obstructive Pulmonary Disease Study Group. Ann Intern Med. 1997;127(12):1072-1079.

40. Koskela J, Kilpelainen M, Kupiainen H, et al. Co-morbidities are the key nominators of the health related quality of life in mild and moderate COPD. BMC Pulm Med. 2014;14:102.

41. Wacker ME, Jorres RA, Karch A, et al. Assessing health-related quality of life in COPD: comparing generic and disease-specific instruments with focus on comorbidities. BMC Pulm Med. 2016;16(1):70.

42. Joo H, Park J, Lee SD, Oh Y-M. Comorbidities of chronic obstructive pulmonary disease in Koreans: a population-based study. J Korean Med Sci. 2012;27(8):901-906.

43. Schnell K, Weiss CO, Lee T, et al. The prevalence of clinically-relevant comorbid conditions in patients with physician-diagnosed COPD: a cross-sectional study using data from NHANES 1999-2008. BMC Pulm Med. 2012;12:26.
International Journal of COPD

\section{Publish your work in this journal}

The International Journal of COPD is an international, peer-reviewed journal of therapeutics and pharmacology focusing on concise rapid reporting of clinical studies and reviews in COPD. Special focus is given to the pathophysiological processes underlying the disease, intervention programs, patient focused education, and self management protocols.

\section{Dovepress}

This journal is indexed on PubMed Central, MedLine and CAS. The manuscript management system is completely online and includes a very quick and fair peer-review system, which is all easy to use. Visit http://www.dovepress.com/testimonials.php to read real quotes from published authors. 